\title{
The Effectiveness of Health Education in Improving Knowledge about Hypoglycemia and Insulin Pen Use among Outpatients with Type 2 Diabetes Mellitus at a Primary Care Hospital in Vietnam
}

\author{
Loan Thi Chu $\mathbb{D}^{1}$, Tran Que Nguyen $\mathbb{D}^{2},{ }^{2}$ Phuong Thu Thi Pham $\mathbb{D}^{3},{ }^{3}$ and Truc Thanh Thai $\mathbb{D}^{4}$ \\ ${ }^{1}$ Faculty of Nursing and Medical Technology, University of Medicine and Pharmacy at Ho Chi Minh City, 217 Hong Bang, \\ District 5, Ho Chi Minh City, Vietnam \\ ${ }^{2}$ Department of Nursing, University Medical Center Ho Chi Minh City, 215 Hong Bang, District 5, Ho Chi Minh City, Vietnam \\ ${ }^{3}$ Hospital for Rehabilitation-Occupational Diseases at Ho Chi Minh City, 313 Au Duong Lan Street, District 8, \\ Ho Chi Minh City, Vietnam \\ ${ }^{4}$ Faculty of Public Health, University of Medicine and Pharmacy at Ho Chi Minh City, 217 Hong Bang, District 5, \\ Ho Chi Minh City, Vietnam \\ Correspondence should be addressed to Truc Thanh Thai; thaithanhtruc@ump.edu.vn
}

Received 31 March 2021; Accepted 28 July 2021; Published 29 August 2021

Academic Editor: Ashraf El-Metwally

Copyright (C) 2021 Loan Thi Chu et al. This is an open access article distributed under the Creative Commons Attribution License, which permits unrestricted use, distribution, and reproduction in any medium, provided the original work is properly cited.

\begin{abstract}
Background. Patients with type 2 diabetes mellitus (T2DM) who have limited knowledge about hypoglycemia and insulin pen use are likely to have hypoglycemia and other complications. Objective. This study aimed to evaluate the effectiveness of health education on knowledge about hypoglycemia and insulin pen use among outpatients with T2DM at a primary care hospital in Vietnam. Methods. A pretest-posttest study was conducted among 80 patients with T2DM at District 11 Hospital in Ho Chi Minh City, Vietnam. At baseline, patients were interviewed through a predefined, structural questionnaire to assess their knowledge about hypoglycemia and insulin pen use. After that, patients underwent an individual health education session about hypoglycemia and insulin pen. One month and two months after this intervention, knowledge about hypoglycemia and insulin pen use were recorded again. Results. The majority were males (65.0\%) and the mean age was 59.6 (standard deviation 8.1, range 35-75) years. Very few patients had good knowledge and proper insulin pen use, with percentages ranging from $13.8 \%$ to $60 \%$. There was a significant improvement of knowledge and practice after the intervention. Such improvement remained high one month and two months after the intervention. Conclusions. The health education intervention is effective in improving knowledge and practice in this population. There is a pressing need for such intervention at primary care hospitals to optimize treatment for patients with T2DM, possibly focusing on those who had characteristics to have the best effectiveness found in this study.
\end{abstract}

\section{Introduction}

Diabetes mellitus (DM) is becoming a global public health problem, characterized by its high prevalence and mortality. Globally, there were more than 460 million people diagnosed with DM in 2019, which is estimated to rise to 700 million by 2045. The prevalence of DM is higher in lowand middle-income countries with the dominance of type
2 diabetes mellitus (T2DM) [1, 2]. Diabetes mellitus is among the leading causes of deaths worldwide, accounting for 1.6 million deaths each year. It also leads to several severe complications to the heart, kidneys, eyes, nerves, blood vessels, and teeth during the course of the disease [3].

In Vietnam, DM is recognized as a major public health burden with approximately 5.76 million people suffering from this condition. The age-adjusted prevalence doubled 
from $2.7 \%$ to $6 \%$ between 2002 and 2017 [4, 5]. Diabetes mellitus is the top cause of mortality and disability combined and represents $3.96 \%$ disability-adjusted life years [6, 7]. Coupled with the aging population in Vietnam, the prevalence of negative impacts of DM on individuals and society presents an urgent demand for proper intervention and management strategies.

Besides lifestyle modification and oral antidiabetic medications, glycemic control is the cornerstone of diabetes management strategy [8]. Insulin therapy, which is essential for treating of both type 1 diabetes mellitus and T2DM, plays a vital role in the maintenance of blood glucose level and reduces diabetes complications. Of the variety of insulin being introduced, the insulin pen appears to be easier to use, portable, accurate, and safe compared to traditional vial and syringe [9, 10]. Effective insulin management using an insulin pen helps patients improve adherence, facilitate self-management of people with DM, prevent the risk of hypoglycemia, and improve the quality of life $[11,12]$.

However, a large body of literature indicates that patients with DM have insufficient knowledge about hypoglycemia $[13,14]$ and insulin use $[15,16]$. The lack of such knowledge will likely result in the increased risk of hypoglycemia and severe complications. Therefore, strategies for enhancing knowledge about hypoglycemia and insulin use in patients with T2DM need to be developed. Among intervention approaches, health education is a key strategy in diabetes management to improve knowledge and practice related to self-management of hypoglycemia and insulin use $[17,18]$. However, to date, little is known about the effectiveness of health education in enhancing the knowledge of hypoglycemia and insulin pen use in outpatients with T2DM who manage their condition at home, particularly in settings like Vietnam.

Therefore, this study is aimed to evaluate the effectiveness of health education on knowledge about hypoglycemia and insulin pen use among outpatients with T2DM at a primary care hospital in Vietnam and to examine the potential factors influencing this effectiveness. Findings from this study can serve as scientific evidence for further development of well-designed healthcare programs to optimize the treatment and to improve the quality of care and quality of life in patients with DM.

\section{Methods}

2.1. Study Design. During December 2019 and May 2020, a pretest-posttest one-group quasi-experimental study was conducted at District 11 Hospital in Ho Chi Minh City, Vietnam. The hospital is a typical district hospital in Vietnam and serves as a primary care clinic for approximately 350 outpatients with T2DM.

2.2. Participants. Outpatients with T2DM aged 18 or more, who had been using insulin pen for at least one month and agreed to participate in this study, were recruited. Patients with comorbidities that affected participation such as those with cognitive impairment were excluded. Patients who could only use insulin pen with help from family members and were unable to use insulin pen on their own were also excluded. Participation was on a voluntary basis.

The sample size calculation was based on the formula to detect the difference in the prevalence of good knowledge and practice before and after the intervention. The estimation for sample size calculation was based on a previous study evaluating the effectiveness of the health education approach in Vietnamese patients with T2DM [19]. With the expected conservative improvement of about 30\%, from $40 \%$ before the intervention to $70 \%$ after the intervention, type one error rate of $5 \%$, a sample size of at least 60 was required to have a statistical power of $90 \%$. In this study, we recruited 84 patients. However, 4 patients refused to participate in the study due to not having enough time for the study.

2.3. Study Procedure. Participants were interviewed using a predefined structural questionnaire to measure their knowledge about hypoglycemia and insulin pen. Participants were asked to demonstrate their use of insulin pen on a model and their level of practice was observed and recorded. After that, patients underwent an individual health education session about hypoglycemia and insulin pen. The researcher first presented these two topics using both Microsoft PowerPoint and hard-copy flashcards. Patients also watched a manual video from the manufacturer on using insulin pen based on the pen they used. Patients were offered 15 minutes to practice using insulin pen. A take-home booklet with information about these two topics was also provided to the patients. The measurement of knowledge and practices as described above was conducted again after the health education session. One month and two months after this intervention, knowledge about hypoglycemia and insulin pen use were recorded again. After each interview and observation during the follow-up, patients underwent an individual health education session to reinforce their knowledge and practice.

2.4. Measurement. The structural questionnaire included three main parts. The first part was about patients' characteristics including sex, age, ethnicity, education level, occupation, and the average monthly income. Information about health status, such as the duration of living with diabetes, the duration of time using insulin pen, and the number of insulin injections per day was also included. To discriminate the effect of this intervention with others, we included information about health counseling services patients received. The second part had five questions to measure knowledge about hypoglycemia, including definition, symptoms, testing, treatment, and prevention of hypoglycemia based on the standards of medical care in diabetes by American Diabetes Association [20] (Appendix Figure 1). One point was given for a correct answer to each question and the overall score was the total score of all five questions, ranging from 0 to 5 . The last part was to measure knowledge about using insulin pen based on the Indian recommendations 2.0 for best practice in insulin injection technique [21]. One point 
was given for a correct answer to each of the 15 questions included. The overall score was the total score of all questions, ranging from 0 to 15 (Appendix Figure 2).

A 15-step checklist was used to evaluate practice on insulin pen use. The checklist was based on EADSG Guidelines and manuals from the manufacturer and included information about the preparation, attach needle, prime the insulin pen, select insulin pen, inject the insulin, and remove needle [22]. The overall evaluation of practice was based on the total score of this checklist, ranging from 0 to 15, and a higher score indicates better practice (Appendix Figure 3).

The questionnaire and checklist were originally developed in Vietnamese and were sent to 3 experts (i.e., experienced nurses and doctors) to review. These were also tested among 10 patients to double-check the logic and wording. A minor revision was made, mostly in the Vietnamese wording, before the main study.

\section{Data Analysis}

Data were entered into EpiData 3.1, cleaned, and doublechecked to ensure no error during data entry. Final data were exported to Stata 16.0 for data analysis. Descriptive statistics used included frequency and percentage for qualitative data. Due to the skewed distribution, scores on knowledge and practice were presented as median and interquartile. The McNemar's Chi-squared tests were used to compare each aspect of knowledge and practice before the intervention and after the intervention. To identify factors associated with the improvement of knowledge and practice after the intervention, Generalized Estimating Equation (GEE) was used. The use of GEE was to consider selfmatched, repeated measure nature of outcomes in this study. All statistical tests were two-sided, and the type one error rate was set at $5 \%$.

3.1. Ethics Approval. All procedures in this study were approved by the Ethics Committee in Bio-Medical Research at the University of Medicine and Pharmacy at Ho Chi Minh City, Vietnam (518/ĐHYD-HĐĐĐ). Approval was also granted by the Director Board of District 11 hospital. Participation was on a voluntary basis, and written informed consent was obtained from all patients participated in this study.

\section{Results}

Among 80 patients with T2DM who participated in this study, the majority were males $(65.0 \%)$ and the mean age was 59.6 (standard deviation 8.1, range 35-75) years. Most participants had been living with diabetes for more than 6 years (76.3\%), used insulin pens for at least one year (71.2\%), and injected insulin at least twice a day $(87.5 \%)$.

The measurement of knowledge about hypoglycemia is presented in Table 1. Before the intervention, very few patients had good knowledge about definition (13.8\%), testing $(30.0 \%)$, treatment $(15.0 \%)$, and prevention $(11.3 \%)$ of hypoglycemia, except hypoglycemia symptoms (60.0\%). Knowledge of these aspects was significantly improved right after the intervention. Although the prevalence of good knowledge one month after the intervention decreased slightly, the figures remained high after two months. A similar pattern was observed in the total score. There was a significantly increased trend in the knowledge about hypoglycemia prevention.

Table 2 presents the levels of knowledge about insulin pen among patients with T2DM. A low level of knowledge about insulin pen was observed in most aspects measured before the intervention. However, there was a significant improvement after the intervention. Such improvement remained high one month and two months after the intervention. The highest increase was recorded in knowledge about pushing the air bubble out before injection (from $20 \%$ before the intervention to $93 \%$ two months after the intervention), the number of injections per needle (10\% and $80.3 \%$ ), consequences of reuse needle so many times $(11.3 \%$ and $81.7 \%)$, and needle treatment after injection (7.5\% and $80.3 \%)$.

Participants had good practice using insulin pen (Table 3). The ceiling effect was observed in almost half of practice evaluated where patients had good practice before the intervention, and thus, there was no more room for improvement. However, patients had improper practice toward priming the insulin pen with low percentages of good practice in this aspect before the intervention ranging from $7.5 \%$ to $13.8 \%$. These figures increased significantly right after the intervention and during the one-month and two-month follow-ups.

The association between patients' characteristics and the overall knowledge and practice scores from all time points were identified using GEE and are presented in Table 4. In overall, significantly higher improvement in knowledge and practice was found among young patients with high monthly income and those who had received counseling about insulin pen since their diagnosis. The high education level was associated with high improvement in knowledge, but not for practice. Interestingly, patients who had received counseling about insulin pen from nurses and doctors since their diagnosis had significantly lower improvement in knowledge about insulin pen compared to those who had received such information from pharmacists.

\section{Discussion}

This study is among the first in Vietnam to evaluate the effectiveness of health education on improving knowledge about hypoglycemia and insulin pen use among outpatients with T2DM at a primary care hospital in Vietnam. The findings highlighted that the levels of knowledge of hypoglycemia and insulin pen use were not optimal at baseline but were significantly improved after the health education intervention. The improvement remained significant after two months.

People with insulin-treated DM are susceptible to hypoglycemia. Therefore, they must have sufficient knowledge to 


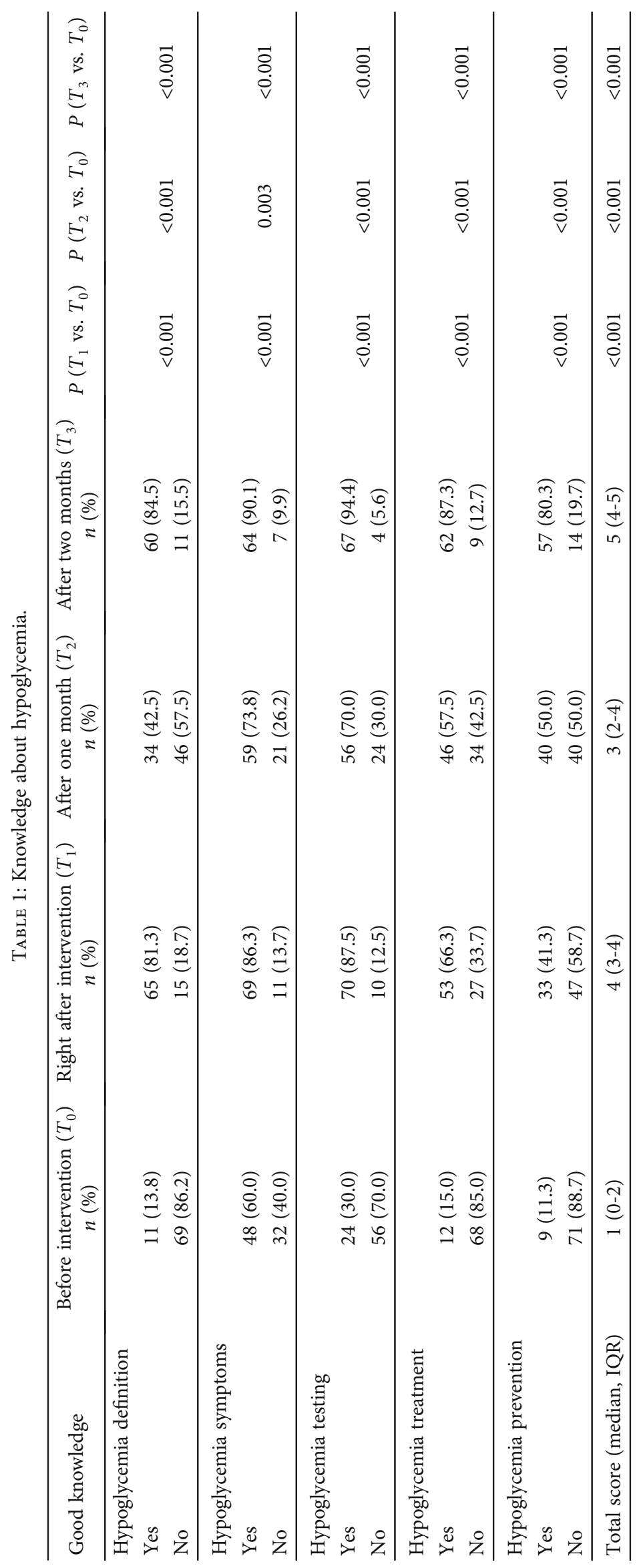




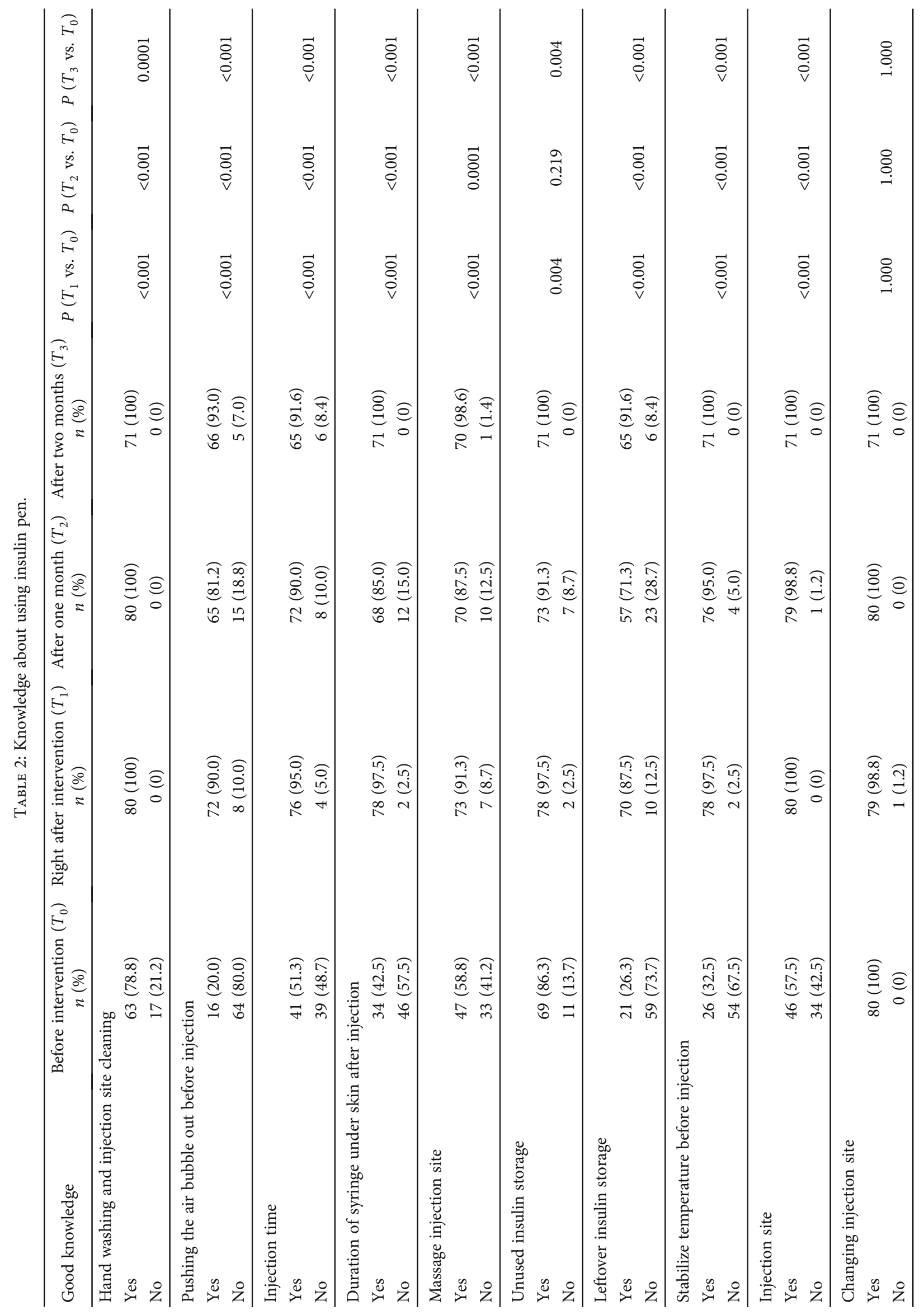




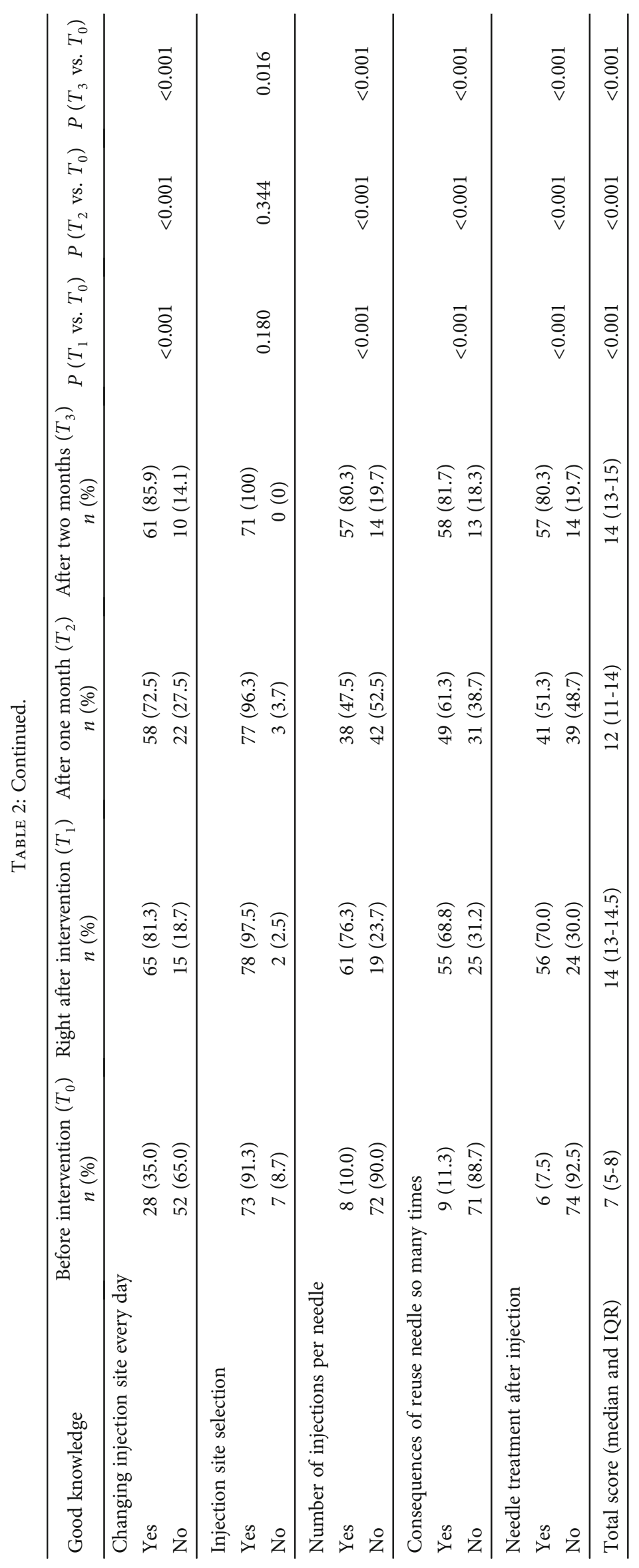




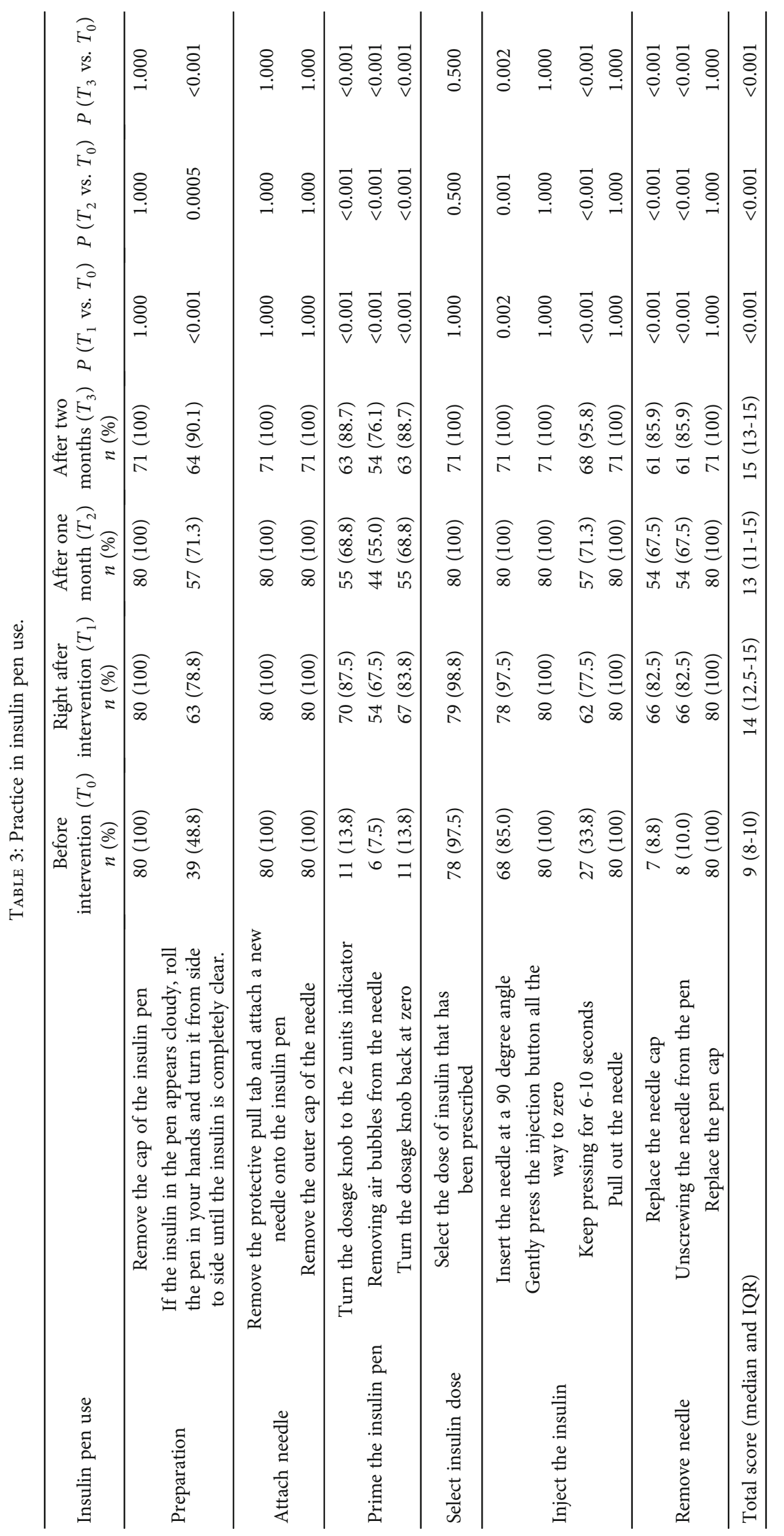


TABLE 4: The association between patients' characteristics and overall knowledge and practice scores.

\begin{tabular}{|c|c|c|c|c|c|c|}
\hline \multirow[t]{2}{*}{ Characteristics } & \multicolumn{2}{|c|}{$\begin{array}{l}\text { Score on knowledge } \\
\text { about hypoglycemia }\end{array}$} & \multicolumn{2}{|c|}{$\begin{array}{l}\text { Score on knowledge } \\
\text { about insulin pen }\end{array}$} & \multicolumn{2}{|c|}{$\begin{array}{l}\text { Score on practice } \\
\text { using insulin pen }\end{array}$} \\
\hline & Coef $(95 \% \mathrm{CI})$ & $P$ & Coef $(95 \%$ CI $)$ & $P$ & Coef $(95 \%$ CI $)$ & $P$ \\
\hline \multicolumn{7}{|l|}{ Demographics } \\
\hline \multicolumn{7}{|l|}{ Ethnicity } \\
\hline Kinh & Ref & & Ref & & Ref & \\
\hline Hoa & $-0.46(-0.92 ;-0.01)$ & 0.046 & $-0.85(-1.50 ;-0.19)$ & 0.011 & $-0.01(-0.57 ; 0.56)$ & 0.985 \\
\hline \multicolumn{7}{|l|}{ Age category (year) } \\
\hline$<50$ & Ref & & Ref & & Ref & \\
\hline $50-60$ & $-0.65(-1.10 ;-0.20)$ & 0.005 & $-0.93(-1.66 ;-0.19)$ & 0.014 & $-0.69(-1.37 ;-0.001)$ & 0.050 \\
\hline$>60$ & $-0.71(-1.12 ;-0.30)$ & 0.001 & $-1.01(-1.69 ;-0.33)$ & 0.004 & $-1.43(-2.11 ;-0.75)$ & $<0.001$ \\
\hline \multicolumn{7}{|l|}{ Sex } \\
\hline Female & Ref & & Ref & & Ref & \\
\hline Male & $0.23(-0.16 ; 0.62)$ & 0.256 & $0.02(-0.53 ; 0.58)$ & 0.932 & $0.53(-0.04 ; 1.09)$ & 0.070 \\
\hline \multicolumn{7}{|l|}{ Education level } \\
\hline Primary school & Ref & & Ref & & Ref & \\
\hline Secondary school & $0.42(-0.04 ;-0.89)$ & 0.074 & $0.62(-0.06 ; 1.29)$ & 0.072 & $0.06(-0.68 ; 0.79)$ & 0.882 \\
\hline High school or over & $0.84(0.43 ; 1.25)$ & $<0.001$ & $0.78(0.28 ; 1.29)$ & 0.002 & $0.50(-0.09 ; 1.09)$ & 0.094 \\
\hline \multicolumn{7}{|l|}{ Occupation } \\
\hline Government employee & Ref & & Ref & & Ref & \\
\hline Retired & $-0.68(-1.69 ; 0.34)$ & 0.190 & $-0.33(-2.34 ; 1.67)$ & 0.745 & $-1.37(-2.82 ; 0.08)$ & 0.065 \\
\hline Others & $-0.83(-1.75 ; 0.09)$ & 0.076 & $-0.69(-2.61 ; 1.22)$ & 0.480 & $-1.05(-2.29 ; 0.19)$ & 0.096 \\
\hline \multicolumn{7}{|c|}{ Average monthly income (million VND) } \\
\hline$<3$ & Ref & & Ref & & Ref & \\
\hline $3-<7$ & $-0.05(-0.48 ; 0.38)$ & 0.829 & $0.31(-0.30 ; 0.92)$ & 0.315 & $0.51(-0.10 ; 1.11)$ & 0.101 \\
\hline$\geq 7$ & $0.75(0.30 ; 1.19)$ & 0.001 & $0.91(0.38 ; 1.45)$ & 0.001 & $1.20(0.59 ; 1.82)$ & $<0.001$ \\
\hline \multicolumn{7}{|l|}{ Health status } \\
\hline \multicolumn{7}{|c|}{ Duration of living with diabetes (year) } \\
\hline$<1$ & Ref & & Ref & & Ref & \\
\hline $1-6$ & $0.31(-0.96 ; 1.58)$ & 0.628 & $0.23(-1.16 ; 1.61)$ & 0.747 & $-0.30(-1.98 ; 1.39)$ & 0.729 \\
\hline$>6$ & $0.53(-0.68 ; 1.75)$ & 0.388 & $0.36(-0.95 ; 1.68)$ & 0.587 & $-0.27(-1.80 ; 1.25)$ & 0.726 \\
\hline \multicolumn{7}{|c|}{ Duration of using insulin pen (year) } \\
\hline$<1$ & Ref & & Ref & & Ref & \\
\hline $1-6$ & $0.18(-0.26 ; 0.62)$ & 0.424 & $0.11(-0.48 ; 0.70)$ & 0.709 & $0.16(-0.46 ; 0.78)$ & 0.604 \\
\hline$>6$ & $0.16(-0.52 ; 0.83)$ & 0.653 & $0.31(-0.45 ; 1.06)$ & 0.427 & $-0.03(-0.89 ; 0.83)$ & 0.951 \\
\hline \multicolumn{7}{|l|}{ Type of insulin pen } \\
\hline Fast-acting insulin & Ref & & Ref & & Ref & \\
\hline Intermediate-acting insulin & $-0.49(-0.96 ;-0.01)$ & 0.044 & $-0.25(-1.04 ; 0.54)$ & 0.531 & $-0.03(-0.96 ; 0.90)$ & 0.956 \\
\hline Long-acting insulin & $-0.65(-1.39 ; 0.08)$ & 0.080 & $-0.19(-1.26 ; 0.87)$ & 0.723 & $0.45(-0.64 ; 1.54)$ & 0.417 \\
\hline \multicolumn{7}{|c|}{ Number of insulin injections per day } \\
\hline 1 & Ref & & Ref & & Ref & \\
\hline 2 & $0.03(-0.65 ; 0.72)$ & 0.922 & $-0.22(-1.20 ; 0.76)$ & 0.664 & $-0.52(-1.29 ; 0.25)$ & 0.182 \\
\hline 3 & $0.10(-0.57 ; 0.78)$ & 0.764 & $-0.31(-1.27 ; 0.65)$ & 0.525 & $-0.74(-2.15 ; 0.67)$ & 0.303 \\
\hline \multicolumn{7}{|c|}{ Health counseling services received since your diagnosis } \\
\hline \multicolumn{7}{|c|}{ Ever received counseling about insulin pen } \\
\hline No & Ref & & Ref & & Ref & \\
\hline Yes & $-0.17(-0.77 ; 0.43)$ & 0.584 & $0.04(-0.99 ; 1.06)$ & 0.947 & $0.12(-1.02 ; 1.25)$ & 0.839 \\
\hline
\end{tabular}


TABLE 4: Continued.

\begin{tabular}{|c|c|c|c|c|c|c|}
\hline \multirow[t]{2}{*}{ Characteristics } & \multicolumn{2}{|c|}{$\begin{array}{l}\text { Score on knowledge } \\
\text { about hypoglycemia }\end{array}$} & \multicolumn{2}{|c|}{$\begin{array}{l}\text { Score on knowledge } \\
\text { about insulin pen }\end{array}$} & \multicolumn{2}{|c|}{$\begin{array}{l}\text { Score on practice } \\
\text { using insulin pen }\end{array}$} \\
\hline & Coef $(95 \% \mathrm{CI})$ & $P$ & Coef $(95 \%$ CI $)$ & $P$ & Coef $(95 \% \mathrm{CI})$ & $P$ \\
\hline \multicolumn{7}{|l|}{ Received counseling about insulin pen from whom } \\
\hline Pharmacist & Ref & & Ref & & Ref & \\
\hline Nurse & $0.15(-0.45 ; 0.75)$ & 0.630 & $-0.73(-1.30 ;-0.17)$ & 0.010 & $-0.11(-0.78 ; 0.56)$ & 0.746 \\
\hline Doctor & $0.32(-0.09 ; 0.75)$ & 0.124 & $-0.94(-1.29 ;-0.60)$ & $<0.001$ & $-0.40(-0.88 ; 0.08)$ & 0.102 \\
\hline \multicolumn{7}{|l|}{ Frequency of receiving counseling about insulin pen } \\
\hline Only the first time when receiving insulin pen & Ref & & Ref & & Ref & \\
\hline Several times during the treatment & $1.73(1.53 ; 1.94)$ & $<0.001$ & $0.26(-0.001 ; 0.53)$ & 0.051 & $1.11(0.82 ; 1.39)$ & $<0.001$ \\
\hline \multicolumn{7}{|c|}{ The last time received counseling about insulin pen (year) } \\
\hline$<1$ & Ref & & Ref & & Ref & \\
\hline $1-5$ & $0.20(-0.31 ; 0.70)$ & 0.446 & $0.25(-0.37 ; 0.86)$ & 0.427 & $0.14(-0.52 ; 0.79)$ & 0.681 \\
\hline$>5$ & $0.17(-0.46 ; 0.80)$ & 0.602 & $0.66(-0.16 ; 1.47)$ & 0.113 & $0.30(-0.49 ; 1.09)$ & 0.453 \\
\hline
\end{tabular}

prevent hypoglycemia and to increase effective selfmanagement. This study found that patients had a relatively high level of knowledge about hypoglycemia symptoms, but inadequate knowledge regarding blood glucose level for hypoglycemia, the importance of glycemic test once hypoglycemia occurs, and measures for treatment and prevention of this condition. The total measuring score indicated an overall poor knowledge of hypoglycemia among participants. These findings agree with previous studies that showed good knowledge about hypoglycemia symptoms [13, 23, 24], and poor knowledge about DM and other aspects of hypoglycemia [13, 14]. An effective management of DM and hypoglycemia is not merely based on the recognition of symptoms but also on the awareness of other important components such as causes, complications, glycemic level monitoring, treatment, and prevention for hypoglycemia onset. Notably, only $11.3 \%$ of patients in our study had good knowledge about prevention, which is much lower than that reported in previous studies. For example, among 15,892 Japanese patients with DM aged 65 or more, $63 \%$ had good knowledge about this aspect [25]. The good knowledge of hypoglycemia prevention was also found in Ethiopia [24].

Significant improvement in knowledge about hypoglycemia was found in our study with a large proportion of participants correctly responded almost all aspects of hypoglycemia at the end of the follow-up, ranging from $80.3 \%$ to $90.1 \%$. In line with the effectiveness of health education in improving knowledge of hypoglycemia, in a systematic review, LaManna et al. (2019) [18] indicated the positive impacts of education on hypoglycemia outcomes, regardless of the intervention approaches or delivery (structured questionnaire, diabetes self-management education and support, individual/group sessions), educators (doctor, nurse, pharmacist, others), participants, study design, multifaceted methods, and the length of interventions. A six-month longitudinal study in India also demonstrated a significant improvement in knowledge, attitude of patients with DM, and a decrease in hypoglycemia symptoms and episodes
[17]. These studies and ours indicated the important role of health education in enhancing knowledge of hypoglycemia among those with DM over time. However, the levels of knowledge of hypoglycemia after the one-month follow-up in our study decreased slightly compared with those recorded right after the intervention. Several likely explanations for this decrease are (1) patients were likely to forget the information if it was provided just once, (2) they might have underestimated the importance of the hypoglycemia occurrence because they had never had hypoglycemia events, or (3) they overtrusted in their capability of self-management. This finding suggested that a more frequent follow-up and repeatable interventions to remain the effectiveness, especially in the early stage of intervention, can be beneficial.

Literature has shown that good knowledge of insulin use is associated with adherence to insulin therapy, effective blood glucose level control, self-management, and reduction of adverse outcomes [26, 27]. However, in our study, participants only had a good awareness of some aspects of insulin pen use. Participants demonstrated low knowledge in several important steps of the procedure, such as lack of pushing out the air bubbles (20\%) and stabilizing pen temperature $(32.5 \%)$ before each injection, improper storage of used insulin pen $(26.3 \%)$, and insulin needle reuse (90\%). In accordance with the present findings, previous studies showed insufficient knowledge about insulin pen use in patients with T2DM $[15,16,28]$. For example, in a recent nationwide survey in Bangladesh, Kamrul-Hasan et al. (2020) [28] found high rates of pen users reusing needles (98.5\%) and reusing them over 10 times (38.9\%), possibly due to a lack of awareness of the possible number of injections per needle and the consequences of needle reuse. The repeated use of insulin needles can lead to distortion, bending, breakage, and complications, including pain, bruising, bleeding, infection, and lipohypertrophy $[16,28]$. The common error of needle reuse has raised a major concern and, in turn, should capture more attention of healthcare professionals. 
Despite the low extent of knowledge about insulin pen, participants in our study had a relatively good insulin injection practice. However, they had errors in some steps of the injection process. Consistent with the literature $[29,30]$, this study found that patients skipped all aspects of priming insulin pen before injection, which could affect the effectiveness of needle and the existence of air bubbles. It has also been suggested to keep the needle under the skin in 6 to 10 seconds before withdrawal to ensure full absorption of insulin, but this practice was found only in around one-third of patients in our study, which is lower than Bari et al. (39\%) and Poudel et al. $(53.5 \%)[29,30]$. Errors in the insulin injection technique also included not removing the needle cap and used needle from pen after injection (90\%) and not mixing cloudy insulin (51.2\%). The proper insulin injection technique is vital in glycemic control, and the incorrect injection technique may lead to poor absorption, thereby severe outcomes such as hypoglycemia, hypoglycemia, lipohypertrophy, or lipoatrophy $[23,31]$.

The present study found a significant increase in participants' knowledge of insulin pen use and injection practice over a two-month follow-up. The improvement remained significant after two months despite a slight decrease in the knowledge of insulin use one month after the intervention. Such improvement is confirmed in a cohort education study in Poland [32] where education intervention results in positive changes in many aspects of insulin use, patients' satisfaction, and blood glucose control. These findings emphasize the vital role of health education, especially continuous assessment and reeducation where healthcare staff can make necessary modification to health education plan for optimizing diabetes management. Moreover, we found that the levels of knowledge about hypoglycemia and insulin use were negatively associated with the increased age and education level. This finding is supported by results from previous studies [13, 33]. The finding implies that healthcare professionals should pay attention to those in this high-risk group in implementing health education.

In terms of treatment, in the current study, patients who had received a high frequency of counseling about insulin pen since their diagnosis were more likely to have good knowledge about hypoglycemia and insulin use. A possible explanation is that people feel difficult to recall what they learn only one time or forget the initial information provided. Therefore, regular education methods such as reeducation or teach-back are demanding during the course of T2DM treatment [28]. In our study, patients received health education at each visit during the follow-up, and thus, both the knowledge and practice remained high after two months. Counselors also have an important role in the changes of knowledge and practice among patients with T2DM. We found that the patients who had received counseling from pharmacists since their diagnosis had better awareness of insulin pen use compared with those who had received such support from nurses and doctors. Hughes, Wibowo, Sunderland, and Hoti (2017) also emphasized the role of pharmacists in diabetes care [34].
It is encouraging to increase the participation of pharmacists and interdisciplinary approaches in enhancing optimal T2DM treatment.

Several implications can be learned from this study. If the low level of good knowledge and practice is true, a large number of patients with T2DM may be at high risk of hypoglycemia and other complications. This indicates an urgent need for further intervention for this population. Moreover, this study has confirmed the previous finding and contributed the evidence of a positive effect of health education on study outcomes and potential factors. However, the application of this intervention requires further modification in clinical practice according to the types of hospital (community/general/university hospital), patients (inpatients/outpatients/patients with T1DM/T2DM), demographic, health-related, and counseling characteristics. This suggests that healthcare providers and healthcare professionals should provide specific interventions aiming to optimize the quality of life of patients with DM.

Findings from our study should be interpreted in light of several limitations. First, this study was conducted at only one primary care hospital in an urban area with a relatively small sample size. This may affect the generalizability of the sample. It is possible that in different settings such as rural or suburban, patients may react differently to the health educational intervention. Further research should include a larger sample size and target population in multiple and various kinds of clinical settings. Second, the relatively short follow-up over a two-month period may not be enough to observe the stability and the long-term effect of the intervention on the study outcomes. We reminded the participants about knowledge and practice at every visit during the study but were unable to know whether the patients have good knowledge and practice without such reminders after the study. Further studies are needed to investigate the intervention intensity needed for the patients to have good knowledge and practice for a long time. Lastly, although our questionnaire was based on current standards and guidelines, the reliability and validity of this questionnaire warrant further investigation. Validated scales to measure knowledge and practice toward hypoglycemia and insulin pen use are needed so that results can be compared across settings.

\section{Conclusions}

Patients with T2DM have a low level of knowledge and practice. Fortunately, the health education intervention is effective in improving knowledge and practice in this population. There is a pressing need for such intervention at primary care hospitals to optimize treatment for patients with T2DM, possibly focusing on those who had characteristics that have the best effectiveness found in this study.

\section{Appendix \\ Questionnaire and the Scoring \\ System (Figures 1-3)}


Knowledge about hypoglycemia

\begin{tabular}{|c|c|}
\hline Question & Score \\
\hline $\begin{array}{l}\text { 1. What blood sugar level is defined as hypoglycemia? } \\
\square \text { 1. Below3 } .9 \mathrm{mmol} / \mathrm{L} \text { (or } 70 \mathrm{mg} / \mathrm{dL} \text { ) } \\
\square 2 . \text { Below } 11.1 \mathrm{mmol} / \mathrm{L} \text { (or } 200 \mathrm{mg} / \mathrm{dL} \text { ) } \\
\square 3 \text {. Below } 7.0 \mathrm{mmol} / \mathrm{L} \text { (hoăc } 126 \mathrm{mg} / \mathrm{dL} \text { ) } \\
\square 4 \text {. Others ......... } \\
\text { घ. Do not know }\end{array}$ & $\begin{array}{c}1 \text { point for answering } \\
\text { "Below } 3.9 \mathrm{mmol} / \mathrm{L} \text { (or } 70 \\
\mathrm{mg} / \mathrm{dL} \text { )" }\end{array}$ \\
\hline $\begin{array}{l}\text { 2. What is the main symptoms of hypoglycemia? } \\
\text { (Multiple choice question) } \\
\square 1 \text {. Sweating } \\
\square 2 \text {. Rapid pulse } \\
\square 3 \text {. Weakness, fatigue } \\
\square 4 \text {. Dizziness } \\
\square 5 \text {. Headache } \\
\square 6 \text {. Hungry, appetite } \\
\square 7 \text { Blurred vision } \\
\square 8 \text {. Anxiety, agitation } \\
\square 9 \text { Tremble } \\
\square 10 \text {. Irritability } \\
\square 11 \text {. Do not know }\end{array}$ & $\begin{array}{l}1 \text { point for answering at } \\
\text { least two symptoms }\end{array}$ \\
\hline $\begin{array}{l}\text { 3. When you have suspicious symptoms of } \\
\text { hypoglycemia, is it necessary to test your blood sugar } \\
\text { level? } \\
\square 1 \text {. Yes } \\
\square 2 \text {. No } \\
\square 3 \text {. Do not know }\end{array}$ & 1 point for answering "Yes" \\
\hline $\begin{array}{l}\text { 4. What are proper treatment for hypoglycemia? } \\
\text { (Multiple choice question) } \\
\square 1 \text {. Eat or drink } 15 \text { grams of fast-acting sugar (glucose } \\
\text { tablets, sugary candy, soft drink, fruit juice, sweets) } \\
\square 2 . \text { Recheck blood sugar levels } 15 \text { minutes after using fast- } \\
\text { acting sugar } \\
\square 3 \text {. If blood sugar level is still low, repeat eating or drinking } \\
\text { fast-acting sugar } \\
\square 4 \text {. Eat or drink short-acting sugar (bread, pyramidal rice } \\
\text { dumpling, low-fat milk, one meal per day) } \\
\square 5 \text {. Do not know }\end{array}$ & $\begin{array}{l}1 \text { point for answering at } \\
\text { least "Eat or drink } 15 \text { grams } \\
\text { of fast-acting sugar (glucos } \\
\text { tablets, sugary candy, soft } \\
\text { drink, fruit juice, sweets)" }\end{array}$ \\
\hline $\begin{array}{l}\text { 5. What are effective ways to prevent hypoglycemia? } \\
\text { (Multiple choice question) } \\
\square \text { 1. Do not eat late/skip meals } \\
\square \text {. Check blood sugar level regularly } \\
\square 3 \text {. Take medication/insulin with right time and right dose } \\
\square 4 \text {. Ensure that insulin dose is consistent with meals } \\
\square \text {. Always bring fast-acting sugar } \\
\square 6 \text {. Light meal before intense activities } \\
\square 7 \text { Restrict alcohol intake. Do not drink without eating } \\
\square 8 \text {. Bring blood sugar monitoring chart and report on the } \\
\text { episodes of hypoglycemia to your doctor in the follow-ups } \\
\square 9 \text {. Do not know }\end{array}$ & $\begin{array}{l}1 \text { point for answering at } \\
\text { least two symptoms }\end{array}$ \\
\hline Total point range & $0-5$ \\
\hline
\end{tabular}

Figure 1: Knowledge about hypoglycemia. 


\begin{tabular}{|c|c|}
\hline \multicolumn{2}{|l|}{ Knowledge about ins } \\
\hline Question & Score \\
\hline $\begin{array}{l}\text { 1. Is it necessary to wash your hands and clean the } \\
\text { injection site before insulin injection? } \\
\square 1 \text {. Yes } \\
\square \text {. No }\end{array}$ & 1 point for answering "Yes" \\
\hline $\begin{array}{l}\text { 2. Is it necessary to prime the insulin pen before each } \\
\text { insulin injection? } \\
\square 1 . \text { Yes } \\
\square 0 \text {. No }\end{array}$ & 1 point for answering "Yes" \\
\hline $\begin{array}{l}\text { *Type of your prescribed insulin: } \\
\text { घ1. Rapid-acting insulin (Novomix, Humalog) } \\
\text { ฉ2. Short-acting and mixed insulin (Wosulin) } \\
\square 3 \text {. Immediate-and long-acting insulin (Lantus) }\end{array}$ & $\begin{array}{l}\text { To evaluate knowledge } \\
\text { depending on participants' } \\
\text { insulin use }\end{array}$ \\
\hline $\begin{array}{l}\text { 3. What is the best interval between insulin injection } \\
\text { and meal? } \\
\square 1.30 \text { minutes before meal } \\
\square 2 \text {. Right before or after meal } \\
\square 3 \text {. Another time point in a day } \\
\square 4 \text {. At a same time each day } \\
\square 5 \text {. Others }\end{array}$ & $\begin{array}{l}1 \text { point for answering } \\
\text { a) "Right before or after } \\
\text { meal" for Novomix, Humalog } \\
\text { or } \\
\text { b) "30 minutes before meal" } \\
\text { for Wosulin } \\
\text { or } \\
\text { c) "At a same time each day" } \\
\text { for Lantus }\end{array}$ \\
\hline 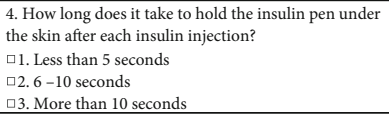 & $\begin{array}{l}1 \text { point for answering "6 - } \\
10 \text { seconds" or "more than } 10 \\
\text { seconds" }\end{array}$ \\
\hline $\begin{array}{l}\text { 5. Should you massage the site after insulin injection? } \\
\square 1 . \text { Yes } \\
\square 0 \text {. No }\end{array}$ & 1 point for answering "No" \\
\hline $\begin{array}{l}\text { 6. Where is the proper place to store unopened } \\
\text { insulin? } \\
\square 1 \text {. In the refrigerator at } 2-8^{\circ} \mathrm{C} \\
\square 2 \text {. Room temperature below } 30^{\circ} \mathrm{C} \\
\square 3 \text {. Others }\end{array}$ & $\begin{array}{l}1 \text { point for answering "In the } \\
\text { refrigerator at } 2-8^{\circ} \mathrm{C} \text { " }\end{array}$ \\
\hline $\begin{array}{l}\text { 7. Where is the proper place to store left over insulin? } \\
\square \text { 1. In the refrigerator at } 2-8^{\circ} \mathrm{C} \\
\square 2 \text {. Room temperature below } 30^{\circ} \mathrm{C} \\
\square 3 . \text { Others }\end{array}$ & $\begin{array}{l}1 \text { point for answering } \\
\text { "Room temperature below } \\
30^{\circ} \mathrm{C} \text { " }\end{array}$ \\
\hline $\begin{array}{l}\text { 8. Is it required to warm up or keep cool the insulin } \\
\text { pen if it is stored in the refrigerator? } \\
\square 1 \text {. Yes } \\
\square 0 \text {. No }\end{array}$ & 1 point for answering "Yes" \\
\hline $\begin{array}{l}\text { 9. What are insulin injection sites? (Multiple choice } \\
\text { question) } \\
\text { व1. Arms } \\
\text { व2. Abdomen } \\
\text { घ3. Thighs } \\
\text { घ4. Buttock }\end{array}$ & $\begin{array}{l}1 \text { point for answering at } \\
\text { least two sites }\end{array}$ \\
\hline $\begin{array}{l}\text { 10. Is it necessary to switch the site each insulin } \\
\text { injection? } \\
\square 1 \text {. Yes } \\
\square 0 \text {. No }\end{array}$ & 1 point for answering "Yes" \\
\hline $\begin{array}{l}\text { 11. In case of injection many times each day, what is } \\
\text { the best way to switch injection sites? } \\
\text { व1.Switch in the same area, } \geq 1 \mathrm{~cm} \text { away from the the } \\
\text { prior injection spot } \\
\square 2 \text {. Switch to any injection sites, not in the same site } \\
\square 3\end{array}$ & $\begin{array}{c}1 \text { point for answering } \\
\text { "Switch in the same area, } \geq 1 \\
\mathrm{~cm} \text { away from the the prior } \\
\text { injection spot" }\end{array}$ \\
\hline $\begin{array}{l}\text { 12. Is it normal to give an insulin injection at the } \\
\text { lipohypertrophy lumps? } \\
\square 1 \text {. Yes } \\
\square 0 \text {. No }\end{array}$ & 1 point for answering "No" \\
\hline $\begin{array}{l}\text { 13. How many times can a needle of insulin pen be } \\
\text { used? } \\
\square 1.1 \\
\square 2.2 \\
\square 3.3 \\
\square 4.4 \\
\square 5 \text {. Others } \\
\end{array}$ & 1 point for answering " 1 " \\
\hline $\begin{array}{l}\text { 14. What are potential consequences of insulin needle } \\
\text { reuse? (Multiple choice question) } \\
\square 1 \text { Needle occlusion } \\
\square 2 \text { Pain, distortion, bruising, bleeding } \\
\square 3 \text { Infection } \\
\square 4 \text { Lipoypertrophy } \\
\square 5 \text { Needle breakage } \\
\square 6 \text { Do not know }\end{array}$ & $\begin{array}{l}1 \text { point for answering at } \\
\text { least two consequences }\end{array}$ \\
\hline $\begin{array}{l}\text { 15. What is the proper treatment of insulin pen needle } \\
\text { used? } \\
\text { व1. Remove the needle from the insulin pen and reuse } \\
\text { व2. Single use and remove } \\
\text { व3. Keep the needle in the insulin pen and reuse } \\
\text { प4. Others }\end{array}$ & $\begin{array}{l}1 \text { point for answering } \\
\text { "Single use and remove" }\end{array}$ \\
\hline Total score range & $0-15$ \\
\hline
\end{tabular}

FIgURE 2: Knowledge about insulin pen use. 
Practice in insulin pen use

\begin{tabular}{|c|c|c|c|c|c|}
\hline Steps & Number & Performance & Miss & Fail & Pass \\
\hline \multirow[b]{2}{*}{ Preparation } & 1 & Remove the cap of the insulin pen & $\square 0$ & $\square 0$ & $\square 1$ \\
\hline & 2 & $\begin{array}{l}\text { If the insulin in the pen appears cloudy, } \\
\text { roll the pen in your hands and turn it from } \\
\text { side to side until the insulin is completely } \\
\text { clear }\end{array}$ & $\square 0$ & $\square 0$ & $\square 1$ \\
\hline \multirow{2}{*}{$\begin{array}{l}\text { Attach } \\
\text { needle }\end{array}$} & 3 & $\begin{array}{l}\text { Remove the protective pull tab and } \\
\text { attach a new needle onto the insulin pen }\end{array}$ & $\square 0$ & $\square 0$ & $\square 1$ \\
\hline & 4 & Remove the outer cap of the needle & $\square 0$ & $\square 0$ & $\square 1$ \\
\hline \multirow{3}{*}{$\begin{array}{l}\text { Prime the } \\
\text { insulin pen }\end{array}$} & 5 & $\begin{array}{l}\text { Turn the dosage knob to the } 2 \text { units } \\
\text { indicator }\end{array}$ & $\square 0$ & $\square 0$ & $\square 1$ \\
\hline & 6 & Removing air bubbles from the needle & $\square 0$ & $\square 0$ & $\square 1$ \\
\hline & 7 & Turn the dosage knob back at zero & $\square 0$ & $\square 0$ & $\square 1$ \\
\hline $\begin{array}{l}\text { Select } \\
\text { insulin dose }\end{array}$ & 8 & $\begin{array}{l}\text { Select the dose of insulin that has been } \\
\text { prescribed }\end{array}$ & $\square 0$ & $\square 0$ & $\square 1$ \\
\hline \multirow{4}{*}{$\begin{array}{l}\text { Inject the } \\
\text { insulin }\end{array}$} & 9 & Insert the needle at a 90 degree angle & $\square 0$ & $\square 0$ & $\square 1$ \\
\hline & 10 & $\begin{array}{l}\text { Gently press the injection button all the } \\
\text { way to zero }\end{array}$ & $\square 0$ & $\square 0$ & $\square 1$ \\
\hline & 11 & Keep pressing for 6-10 seconds & $\square 0$ & $\square 0$ & $\square 1$ \\
\hline & 12 & Pull out the needle & $\square 0$ & $\square 0$ & $\square 1$ \\
\hline \multirow{3}{*}{$\begin{array}{l}\text { Remove } \\
\text { needle }\end{array}$} & 13 & Replace the needle cap & $\square 0$ & $\square 0$ & $\square 1$ \\
\hline & 14 & Unscrewing the needle from the pen & $\square 0$ & $\square 0$ & $\square 1$ \\
\hline & 15 & Replace the pen cap & $\square 0$ & $\square 0$ & $\square 1$ \\
\hline \multicolumn{3}{|r|}{ Total score range } & \multicolumn{3}{|c|}{$0-15$} \\
\hline
\end{tabular}

Figure 3: Practice in insulin pen use.

\section{Data Availability}

The data used to support the findings of this study are restricted by the local ethics committee in order to protect patient privacy. Data are available from Truc Thanh Thai, email: thaithanhtruc@ump.edu.vn for researchers who meet the criteria for access to confidential data.

\section{Disclosure}

This research did not receive any specific grant from funding agencies in the public, commercial, or not-for-profit sectors.

\section{Conflicts of Interest}

The authors declare that they have no conflicts of interest.

\section{Authors' Contributions}

TTT and LTC designed the study. LTC collected the data. TTT and LTC analyzed and validated the data. TQN and PTTP interpreted the data. TTT, LTC, TQN, and PTTP drafted the manuscript and approved the final manuscript.

\section{Acknowledgments}

The authors would like to thank the director board of District 11 hospital, Ho Chi Minh City for continuous support during the study.

\section{References}

[1] International Diabetes Federation, "Diabetes facts \& figures," 2020, https://www.idf.org/aboutdiabetes/what-is-diabetes/ facts-figures.html/.

[2] World Health Organization, "Diabetes," 2020, https://www .who.int/news-room/fact-sheets/detail/diabetes/.

[3] International Diabetes Federation, "Diabetes complications," 2020, https://www.idf.org/aboutdiabetes/complications.html/.

[4] International Diabetes Federation, IDF Diabetes Atlas - Ninth edition 2019, International Diabetes Federation, 2019.

[5] K. T. Nguyen, B. T. T. Diep, V. D. K. Nguyen, H. van Lam, K. Q. Tran, and N. Q. Tran, "A cross-sectional study to evaluate diabetes management, control and complications in 1631 patients with type 2 diabetes mellitus in Vietnam (DiabCare Asia)," International Journal of Diabetes in Developing Countries, vol. 40, no. 1, pp. 70-79, 2020. 
[6] Institute for Health Metrics and Evaluation, "Viet Nam," 2017, http://www.healthdata.org/vietnam/.

[7] Institute for Health Metrics and Evaluation, "GBD Compare Viz Hub," 2019, https://vizhub.healthdata.org/gbd-compare/.

[8] P. E. Cryer, "The barrier of hypoglycemia in diabetes," Diabetes, vol. 57, no. 12, pp. 3169-3176, 2008.

[9] T. S. Bailey and S. V. Edelman, "Insulin pen use for type 2 Diabetes-A clinical perspective," Diabetes Technology \& Therapeutics, vol. 12, no. S1, pp. S-86-S-90, 2010.

[10] W. Ramadan, N. Khreis, and W. Kabbara, "Simplicity, safety, and acceptability of insulin pen use versus the conventional vial/syringe device in\&nbsp;patients with type 1 and type 2 diabetes mellitus in Lebanon," Patient Preference and Adherence, vol. 9, pp. 517-528, 2015.

[11] R. M. Cuddihy and S. K. Borgman, "Considerations for Diabetes," American Journal of Therapeutics, vol. 20, no. 6, pp. 694-702, 2013.

[12] P. Lasalvia, J. E. Barahona-Correa, D. M. Romero-Alvernia et al., "Pen devices for insulin self-administration compared with needle and Vial," Journal of Diabetes Science and Technology, vol. 10, no. 4, pp. 959-966, 2016.

[13] A. Ejegi, A. J. Ross, and K. Naidoo, "Knowledge of symptoms and self-management of hypoglycaemia amongst patients attending a diabetic clinic at a regional hospital in KwaZuluNatal," African Journal of Primary Health Care \& Family Medicine, vol. 8, no. 1, pp. 1-6, 2016.

[14] T. P and V. M, "knowledge on hypoglycemia among patients with diabetes mellitus," Asian Journal of Pharmaceutical and Clinical Research, vol. 11, no. 1, pp. 236-239, 2018.

[15] S. Priscilla, S. Malarvizhi, A. K. Das, and V. Natarajan, "The level of knowledge and attitude on insulin therapy in patients with diabetes mellitus in a teaching hospital of Southern India," Journal of Family Medicine and Primary Care, vol. 8, no. 10, pp. 3287-3291, 2019.

[16] B. Tosun, F. I. Cinar, Z. Topcu et al., "Do patients with diabetes use the insulin pen properly?," African Health Sciences, vol. 19, no. 1, pp. 1628-1637, 2019.

[17] G. Bhutani, S. Kalra, S. Lamba, P. K. Verma, R. Saini, and M. Grewal, "Effect of diabetic education on the knowledge, attitude and practices of diabetic patients towards prevention of hypoglycemia," Indian Journal of Endocrinology and Metabolism, vol. 19, no. 3, pp. 383-386, 2015.

[18] J. LaManna, M. L. Litchman, J. K. Dickinson et al., "Diabetes education impact on hypoglycemia outcomes: a systematic review of evidence and gaps in the literature," The Diabetes Educator, vol. 45, no. 4, pp. 349-369, 2019.

[19] N. T. Hai, D. T. Hang, D. V. Dung, N. H. Duy, and N. X. Bach, "Survey Onknowledge and impacts of medication consultation in diabetes patients in Phuc Yen Region General Hospital," Scientific Journal of the National University in Hanoi, vol. 33, no. 2, pp. 85-93, 2017.

[20] American Diabetes Association, "6. Glycemic Targets:Standards of medical care in diabetes-2019," Diabetes Care, vol. 42, Supplement 1, pp. S61-s70, 2019.

[21] N. Tandon, M. S. V, A. Mithal et al., "Forum for injection technique (FIT), India: the Indian recommendations 2.0, for best practice in insulin injection technique, 2015," Indian journal of endocrinology and metabolism, vol. 19, no. 3, article 152762, pp. 317-331, 2015.

[22] S. Bahendeka, R. Kaushik, A. B. Swai et al., "EADSG guidelines: insulin storage and optimisation of injection technique in diabetes management," Diabetes Therapy, vol. 10, no. 2, pp. 341-366, 2019.

[23] C. Bhaska, S. Chittawar, and T. Dubey, "Study of knowledge regarding insulin and injection technique, hypoglycemia and its management among the diabetes patients: a study from single centre," International Journal of Medicine Research, vol. 4, no. 2, pp. 67-71, 2019.

[24] E. A. Muche and B. T. J. P. Mekonen, "Hypoglycemia prevention practice and its associated factors among diabetes patients at university teaching hospital in Ethiopia: Cross-sectional study," PLoS One, vol. 15, no. 8, article e0238094, 2020.

[25] M. Fukuda, K. Doi, M. Sugawara, Y. Naka, and K. Mochizuki, "Survey of hypoglycemia in elderly people with type 2 diabetes mellitus in Japan," Journal of Clinical Medicine Research, vol. 7, no. 12, pp. 967-978, 2015.

[26] U. S. Jasper, M. C. Opara, E. B. Pyiki, and O. Akinrolie, "Knowledge of insulin use and its determinants among Nigerian insulin requiring diabetes patients," Journal of Diabetes \& Metabolic Disorders, vol. 13, no. 1, pp. 1-8, 2014.

[27] T. Mariye, A. Girmay, T. Birhanu et al., "Adherence to insulin therapy and associated factors among patients with diabetes mellitus in public hospitals of Central Zone of Tigray, Ethiopia, 2018: a cross-sectional study," The Pan African Medical Journal, vol. 33, 2019.

[28] A. B. Kamrul-Hasan, A. K. Paul, M. N. Amin et al., "Insulin injection practice and injection complications - results from the Bangladesh insulin injection technique survey," European Endocrinology, vol. 16, no. 1, pp. 41-48, 2020.

[29] B. Bari, M. A. Corbeil, H. Farooqui et al., "Insulin injection practices in a population of Canadians with diabetes: an observational study," Diabetes Therapy, vol. 11, no. 11, pp. 2595-2609, 2020.

[30] R. S. Poudel, S. Shrestha, R. M. Piryani, B. Basyal, K. Kaucha, and S. Adhikari, "Assessment of insulin injection practice among diabetes patients in a tertiary healthcare centre in Nepal: a preliminary study," Journal of Diabetes Research, vol. 2017, Article ID 8648316, 6 pages, 2017.

[31] J. Pledger, D. Hicks, F. Kirkland, and S. Down, "Importance of injection technique in diabetes," Journal of Diabetes Nursing, vol. 16, no. 4, 2012.

[32] M. Gorska-Ciebiada, M. Masierek, and M. Ciebiada, "Improved insulin injection technique, treatment satisfaction and glycemic control: results from a large cohort education study," Journal of Clinical \& Translational Endocrinology, vol. 19, article 100217, 2020.

[33] S. K. Sharma and R. Kant, "Awareness of symptoms and early management of hypoglycemia among patients with diabetes mellitus," Endocrinology Association of Nepal, vol. 1, no. 1, pp. 11-16, 2017.

[34] J. D. Hughes, Y. Wibowo, B. Sunderland, and K. Hoti, “The role of the pharmacist in the management of type 2 diabetes: current insights and future directions," Integrated Pharmacy Research \& Practice, vol. 6, pp. 15-27, 2017. 